\title{
Formação ao Longo da Vida (FLV): o que o trabalhador quer aprender?
}

\author{
Antônio de Pádua Nunes Tomasi ${ }^{1}$ \\ tomasi@uai.com.br \\ Jane Eyre Rios de Macêdo Ferreira ${ }^{2}$ \\ janeeyre@engetower.com.br
}

\section{Resumo}

A Formação ao Longo da Vida porta a ideia do educando como protagonista do seu processo educativo, de aquisição permanente de conhecimentos em todos os níveis da sociedade e de desenvolvimento da pessoa por meio do acesso ao conhecimento. Assim, nem sempre o que o aluno trabalhador deseja aprender faz parte dos saberes valorizados pelo mercado de trabalho e, quando faz parte, nem sempre ele vai ao encontro desses saberes para atender o mercado. Ainda que ele faça uso dos diplomas e certificados obtidos nos cursos, uma pesquisa realizada com trabalhadores da construção civil sugere que eles estão mais preocupados em compreender o seu fazer cotidiano a partir do acesso a saberes por eles denominados de teóricos. Eles estão interessados, ainda, em adquirir uma linguagem, seja acadêmica, seja técnica, que lhes permita não apenas melhor expor e valorizar os seus conhecimentos, mas também dialogar de igual para igual com os seus superiores.

Palavras chave: Formação ao Longo da Vida, práticas educativas, trabalhadores da construção civil

1 Doctorat de Sociologie pela Université Paris VII - Université Denis Diderot. Professor do Centro Federal de Educação Tecnológica de Minas Gerais CEFET/MG.

2 Mestre em Educação Tecnológica - CEFET/MG. Professora da Rede Municipal de Belo Horizonte/MG. 


\title{
Lifelong learning: what the worker want to learn?
}

\begin{abstract}
Lifelong Learning bears the idea of the learners playing the major role in their learning process in the permanent acquisition of knowledge in all levels of society and obtaining personal development by means of the access to knowledge. However, what the students want to learn is not usually what the labor market values, and when it happens, they do not often search for this knowledge in order to comply with the demands of the labor market. Even if they make use of the certificates and diplomas obtained, a research carried out with civil construction workers suggests that they are more concerned about understanding their own work since they have learned theoretical aspects of their job. They are also interested in acquiring vocabulary, either academic or technical, which allows them not only to better expose and value their knowledge but also to talk as an equal to their superiors.
\end{abstract}

Key-words: Lifelong Learning, educational practices, civil construction workers

\section{Introdução}

Ainda que alguns prefiram detectar na Formação ao Longo da Vida (FLV) marcas que a identificam com os interesses patronais relacionados à adaptação do trabalhador e, para isso, não precisam fazer grande esforço para encontrar elementos que favorecem essa identificação, este artigo prefere outro entendimento, qual seja, o que teria como uma de suas referências os movimentos sociais, que marcaram os anos 1960 no Brasil e noutras partes do mundo. Esses movimentos anunciavam a "educação popular" como um caminho democrático da educação a ser seguido.

Estudos de pesquisadores da formação profissional, entre eles os encontrados no Conservatoire National des Arts et Métiers (CNAM), na 
França, tais como os de Merle (2006), Meirieu (1998), entre outros, portam nítidos sinais de identificação com esses movimentos.

Assim, a formação profissional, no sentido da FLV e para esses pesquisadores, viabiliza-se na relação livre e respeitosa de formadores e alunos trabalhadores. Ela conduz o aluno trabalhador a compreender a sua prática profissional construída na situação de trabalho, permitindo que ele desenvolva a sua autonomia, seus projetos pessoais e profissionais. E, ainda, participa do processo de desenvolvimento da pessoa por meio da aquisição permanente de conhecimentos em todos os níveis da sociedade.

A FLV, nessa perspectiva, apresenta-se, diferentemente da formação profissional como adaptação do trabalhador ao mercado e às suas demandas. Aliás, a formação profissional como adaptação acompanhou de perto esforços brasileiros, mesmo embrionários, de industrialização. No Brasil, a Escola de Artes e Ofícios criada em 1909, mais tarde denominada Escola Técnica Federal, depois Centro Federal de Educação Tecnológica e recentemente Instituto Federal de Educação, Ciência e Tecnologia, e o Serviço Nacional de Aprendizagem dos Industriários (SENAI) criado em 1942, entre outros, são exemplos clássicos, ainda que aquele tenha, ao longo do tempo, procurado se distanciar dessa perspectiva. $\mathrm{Na}$ Europa e, em especial, na França, a intervenção do Estado na formação profissional, sobretudo no século passado, faz-se igualmente na cadência do desenvolvimento da indústria e de suas necessidades. A naturalidade como era e ainda é vista a relação de parceria entre escola e empresa pode ser observada, por exemplo, em estudos de um dos mais importantes sociólogos do trabalho, o francês George Friedmann (1972), aliás, um dos fundadores dessa sociologia na França, para quem era imperdoável o desmonte da atividade de trabalho afeita ao operário submetido à organização taylorista, mas era ao mesmo tempo aceitável que a escola procurasse na indústria ou no mundo do trabalho, de modo geral, os saberes que deveriam ser, por ela, transferidos aos trabalhadores. Ou seja, uma escola e uma formação profissional que não tinham a qualificação como um atributo do trabalhador, mas do posto de trabalho.

A emergência, em especial na Europa, das discussões sobre a FLV 
ocorre no mesmo período em que outra discussão se fazia na academia e no mundo da produção, qual seja a das competências. Não se está aqui apontando qualquer relação entre as duas temáticas, entretanto, há que se considerar que a formação do trabalhador à luz do modelo taylorista, que se impôs quase soberanamente durante décadas do século passado, essencialmente adaptativa, não mais atende inteiramente às demandas postas na atualidade por grande parte do mercado ou, mais precisamente, do mundo da produção. Como observa Dugué (2004) trata-se de um modelo esgotado, ainda que, complementaríamos, permaneça vivo e alguns de seus princípios possam ser identificados em sistemas de produção atuais. Na mesma medida, as exigências de flexibilização da produção e das relações de trabalho observadas hoje parecem apontar para outras demandas dirigidas ao trabalhador e à sua formação. É aí, então, que pode ocorrer um equívoco: travestida de uma formação profissional comprometida com o trabalhador e seus projetos de desenvolvimento pessoal e profissional, a FLV pode apenas encobrir uma nova modalidade adaptativa da formação profissional e do trabalhador às novas formas de produção.

Por mais importante que seja essa discussão não é nosso objetivo avançar nessa direção, nesse trabalho, assim como não pretendemos demonstrar as proximidades acima lembradas entre a FLV e a "educação popular", visto que se trata de um recorte de uma pesquisa mais ampla. Pretendemos tão somente identificar elementos na busca que faz o trabalhador de formação profissional, que o aproximam muito mais de si mesmo, dos seus desejos e projetos pessoais e profissionais, do que do mercado e suas demandas. De modo geral, esses elementos, são frequentemente encobertos pela escola e, em especial, pelos programas de formação profissional, preocupados em transferir saberes ao trabalhador ou formá-lo para o mercado. Nesse sentido, a identificação desses elementos e tão somente isso seria a contribuição a ser oferecida por esse trabalho. Para tanto é de se esperar, como nos faz pensar a FLV, que o aluno trabalhador sabe o que quer aprender, daí, então, a questão formulada: o que os trabalhadores querem aprender?

Essa questão, visivelmente provocativa, encobre inúmeros pontos de 
vista que dão sentidos aos mais diversos entendimentos, que oscilam entre o reconhecimento ou não da capacidade do trabalhador de conduzir a sua própria formação profissional, como de resto outras dimensões da sua vida. Para que ele seja capaz de conduzir a sua própria formação profissional é de se esperar, como passo primeiro, que ele saiba o que quer aprender.

Ainda que não pretendamos perder de vista as dimensões estruturais de uma sociedade que insiste em se transformar (economia, cultura, mercado, tecnologia) e com ela assegurar o diálogo, metodologicamente este trabalho busca, de preferência, o indivíduo, procurando, assim, aproximar-se do trabalhador que se dirige à escola à procura de formação profissional.

A pesquisa na qual se encontra fundamentado este trabalho foi realizada a partir de uma única categoria profissional, no caso de trabalhadores da construção civil da Região Metropolitana de Belo Horizonte, alunos do curso de Gestão de Obras oferecido pelo Grupo de Pesquisa PROGEST/ CEFET-MG. Além deles foram ouvidos, também, formadores desse mesmo curso. Desde logo se adverte que qualquer generalização que se faça, inclusive para trabalhadores da mesma categoria profissional, não se faz sem risco de equívocos. O curso foi escolhido exatamente porque guarda certa peculiaridade, como por exemplo, os trabalhadores que o buscam assim o fazem por iniciativa própria e não por iniciativa de terceiros, de empresas nas quais trabalham ou pretendem trabalhar; o curso é ministrado por alunos dos cursos de Engenharia do CEFET-MG, que atuam como formadores, e não por professores.

Como este artigo recorta uma pesquisa mais ampla financiada pela FAPEMIG, discutindo apenas alguns dados coletados, que podem nos ajudar a compreender o que os trabalhadores que buscam a formação profissional oferecida pela escola querem aprender serão discutidos tão somente depoimentos extraídos de entrevistas realizadas com alunos trabalhadores do curso de Gestão de Obras e com formadores.

Ainda que os resultados obtidos não sejam precisos quanto ao que os alunos trabalhadores querem aprender eles mostram com muita clareza que eles buscam o que denominam de "teórico" e, ainda, a posse de uma linguagem, em especial a técnica. Aparentemente, o acesso a esses saberes poderia, no entendimento deles, ajudá-los na compreensão do fazer 
profissional, na comunicação nas relações de trabalho e na exposição de seus conhecimentos. Enfim, no reconhecimento de suas competências.

\section{Da educação à formação. Culturas e práticas educativas em questão}

De modo geral, o professor, quando entra em sala de aula munido dos seus planos de ensino e de aula, está imbuído da ideia de que é portador de um saber, que deve ser repassado aos alunos e esses devem absorver todos os saberes na forma, na ordem e nos conteúdos definidos pela pedagogia, legitimados e exigidos pelos órgãos governamentais de educação, pela escola e por ele, professor. Prevalece, então, na escola e na relação professor-aluno, o que o primeiro quer ou acha que deve ser ensinado e como deve ser ensinado e não o que o segundo quer aprender ou como aprender. O ponto de equilíbrio dessa relação se encontra muito mais no ensinar do que no aprender.

Essa relação é entendida por Durkheim (1973) como coercitiva, ou seja, imposta às pessoas independentemente de sua vontade. Uma ação unilateral dirigida pelos adultos aos jovens, incapazes de reagir diante da ação educativa. Trata-se de uma ação, no entendimento do sociólogo, importante para o processo de construção da coesão social.

Diferentemente disso seria reconhecer o aluno como protagonista da sua educação, ou seja, aquele que decide o que aprender e como aprender. Em outras palavras seria reconhecê-lo como sujeito do seu próprio processo de aprendizagem ou como o educando que se educa. Evidentemente isso não se daria de forma solitária, mas na relação com o outro que, longe de ser o possuidor de um saber, seria muito mais o facilitador da aprendizagem. Facilitador no sentido mesmo utilizado por Rogers (1974) em sua obra Grupos de encontros, entre outras.

Barbier (2009), entre muitos autores, nos dá a sua contribuição. Para ele trata-se de ações educativas que nos remetem a culturas educativas diferentes. A primeira delas, que ele denomina de "culturas do ensino", tem como referência o saber que é possuído pelo professor, figura emblemática do processo, que o transfere ao aluno sob a forma de conhecimento. Nesse caso, o tempo e o espaço educativo são organizados 
a partir de uma lógica da comunicação.

A segunda, denominada de "culturas da formação", concebe a ação educativa em relação explícita com atividades de referência e define a aprendizagem como uma noção próxima à de capacidade. Ela organiza, portanto, o espaço educativo como um espaço de produção de novas capacidades. Para esse autor, a figura emblemática dessa cultura é o formador, que não é um detentor ou um transmissor de saberes, mas um organizador de situações de aprendizagens, um facilitador.

Ele se refere, ainda, a uma terceira cultura ou "culturas do desenvolvimento de competências" em que o contexto educativo é o de formação integrada à atividade, ao trabalho. As aprendizagens estão relacionadas ao desenvolvimento de competências que acontecem em espaços de ação "real" dos sujeitos. Nessa cultura a figura emblemática é a do acompanhante, do tutor, cujo papel é o de acompanhar e de intervir junto aos sujeitos em suas ações nesses espaços.

Longe de estabelecer uma crítica a essas culturas, ele afirma que elas coexistem em diferentes momentos da ação educativa e toma a formação em alternância, que para ele é um dispositivo que conjuga vários espaços educativos, como exemplo de tal coexistência.

No Brasil, não há grandes novidades nessa discussão. A escola, as práticas educativas e a relação professor-aluno, sobretudo na forma como esta última se dá são há algum tempo objetos de reflexão, mas também de críticas, dentre as quais destacamos a que se encontra na obra Cuidado, Escola publicada em 1980, apresentada por Paulo Freire e de autoria de Babette Harper, Claudius Ceccon, Miguel Darcy de Oliveira e Rosiska Darcy de Oliveira, membros da equipe do Instituto de Ação Cultural (IDAC).

Da mesma forma, não há grandes novidades na França. Nesse país, reflexões mais recentes, mas também críticas, ganham relevância pelas mãos de pesquisadores do Conservatoire National des Arts et Métiers (CNAM), entre eles, Philipe Meirieu (1998), Vincent Merle (2006), Guy Jobert (2006) e Bernard Fourcade (2009). Da mesma forma, em Portugal, os estudos de Licínio C. Lima (2007) e de Ana Luisa Pires (2005) nos oferecem uma importante contribuição para compreendermos a referida questão.

Ressaltem-se as contribuições dos estudiosos da formação profissional 
ligados ao CNAM, que apontam para uma identificação das ações educativas acima citadas com as noções de educação e de formação, que, para eles, não se confundiriam. Assim, enquanto a noção de educação deve ser reservada à infância, quando o adulto decide o que a criança deve aprender, a noção de formação deve ser reservada ao adulto, que decide, ele mesmo, o que aprender e como aprender. Em outras palavras, nós diríamos que a escolha que o trabalhador faz livre e conscientemente do que quer aprender e como quer aprender é uma referência importante da FLV.

No esforço de construção da noção de FLV eles tomam como ponto de partida a distinção que veem nos termos "educação" e "formação". Para eles o primeiro termo é entendido como uma ação dos adultos dirigida às crianças, que devem ser educadas para se inserir socialmente, incorporar conhecimentos, valores, princípios morais e éticos; o segundo termo, por sua vez, é entendido como uma ação dos próprios adultos, que, com a participação de um terceiro, o formador, educam-se. Ou seja, participam do seu próprio processo de formação. No caso, a formação profissional, mas também a inicial ou permanente. Eles destacam a autonomia como um elemento central da FLV.

Segundo Meirieu (2005), que partilha integralmente dessa ideia, a educação traz consigo uma dimensão totalitária, "tirânica" mesmo. A formação, por outro lado, ressalta, inscreve-se num projeto, numa antecipação do futuro pessoal ou profissional. Ou seja, o indivíduo deve ser o sujeito principal da sua formação.

Essas reflexões conduziram, ainda, à construção de uma noção de formação que procura escapar ao entendimento que a identifica com iniciativas que buscam oferecer uma segunda chance aos que não tiveram a oportunidade de se educarem na infância, conhecida no Brasil como Educação de Jovens e Adultos (EJA) ou, ainda, com iniciativas que investem na formação da mão de obra voltada para a adaptação ao trabalho e às suas mudanças, a exemplo dos cursos oferecidos por entidades patronais, seja no Brasil ou mesmo na Europa. Diferentemente dessas práticas educativas seria a FLV, que não se confunde com outras como a Educação ao Longo da Vida e a Aprendizagem ao Longo da Vida, que, vez por outra, aparecem equivocamente como sinônimas. 


\section{Educação, formação e aprendizagem ao longo da vida}

Vale esclarecer que nos anos 1920, na Inglaterra, já havia registro de uma preocupação com a formação para toda a vida, então denominada de Lifelong Learning. Essa denominação encontra tradução na língua francesa como Éducation, Formation e Apprentissage Tout au Long de la Vie ou Educação, Formação e Aprendizagem ao Longo da Vida. Separadamente, entretanto, essa denominação aponta para entendimentos diferentes, ainda que tenha como matriz ou ponto de partida a educação permanente (LIMA, 2007). Esses entendimentos são, em seguida, apresentados de forma abreviada.

\subsection{A Educação ao Longo da Vida}

Com importante visibilidade na Europa nos anos 1970, a noção reaparece em 1990, num contexto totalmente diferente do anterior, quando o continente passa a ser marcado pela competitividade e lutas contra o desemprego (FOURCADE, 2009). A Educação ao Longo da Vida passa ser entendida, então, como o processo educativo que visa a desenvolver as capacidades, potencialidades, conhecimentos e atitudes, quase sempre, associadas ao ser humano quando criança ou jovem (PIRES, 2005).

Ela é também, segundo Boshier (1998), portadora de uma política pública muito presente e de ações deliberadas. É preciso que "um ator governamental" desenvolva políticas e conceda recursos que se inscrevam tanto no contexto formal, ligado aos sistemas de educação e de formação, quanto no não formal, ou seja, fora dos sistemas e relacionados às organizações da sociedade civil, ou informal, quando a atividade é organizada pelo próprio indivíduo.

\subsection{A Aprendizagem ao Longo da Vida}

Essa noção, por sua vez, é compreendida como integrando a dimensão sociocultural e não apenas psicológica. É um conceito que ultrapassa a aprendizagem realizada em contextos formais - balizado por instituição, 
programas e objetivos pré-determinados - significa a aprendizagem em sentido lato, que tanto pode ser realizada dentro como fora das instituições de educação/formação, quanto pode ocorrer em qualquer tempo ou momento da vida da pessoa. (USHER, BRYANT, JOHNSTON, 1997).

A noção de aprendizagem remete diretamente à responsabilidade do indivíduo em relação ao seu percurso educativo, levando-se em conta as necessidades relacionadas aos projetos individuais e às ofertas de educação e formação colocadas à sua disposição. Para garantir essa oferta é preciso que a Educação ao Longo da Vida desenvolva políticas e conceda recursos que se inscrevam tanto no contexto formal, quanto no contexto não formal ou informal de espaços de formação (BOSHIER, 1998).

\subsection{A Formação ao Longo da Vida (FLV)}

A emergência da noção de FLV pode caracterizá-la, também, como um prolongamento da educação permanente, mais especificamente da formação continuada e da formação popular. Para Alain Bournazel (2001, apud Fourcade, 2009, p.916) ela estaria relacionada à educação e à formação permanente, que desde os anos 1960 balizam principalmente os cenários europeus, sobretudo por meio das organizações internacionais.

Muito embora se queira ressaltar o caráter de apropriação do conhecimento pelo indivíduo, a construção desse conhecimento a partir das relações estabelecidas no interior dessa prática educativa ou a formação do espírito humano como marcas da FLV ou, ainda, queira-se lembrar suas raízes na "educação popular", não se deve esquecer que ela tem origem nas preocupações de organismos europeus que, desde os anos 1960, propõem instaurar um sistema de educação permanente ao longo da vida, para responder às necessidades das novas demandas da economia - competências técnicas requisitadas no espaço da automatização no que toca ao setor industrial - e à necessidade de igualdade social, dando acesso à educação e à formação dos indivíduos que tinham abandonado muito cedo a educação inicial (MÉHAUT, 2004).

De fato, não obstante a ampla dimensão educacional e social da FLV, a sua ligação à esfera do trabalho já estava definida desde as primeiras 
abordagens da Organização para Cooperação e Desenvolvimento Econômico (OCDE), em 1973, que preconizava a necessidade de "[...] se promover ao longo da vida a alternância de períodos de educação e de formação, com períodos de trabalho e de lazer, aos quais seriam assimilados os tempos de desemprego e de aposentadoria ativa" (FOURCADE, 2009, p.921).

O retorno das discussões sobre a FLV nos anos de 1990 reforça o entendimento de que houve nos modelos de organização do trabalho uma passagem da lógica da operação para a lógica dos acontecimentos (ZARIFIAN, 1996). Dessa maneira a colocação em prática da lógica de competências impõe aos assalariados buscarem formações que os tornem capazes de aprender novas competências e a elas se adaptarem. Nesse contexto, para Fourcade $(2009$, p. 943) não é suficiente "aprender a aprender". Para ele é necessário que as novas competências adquiridas sejam visíveis aos outros, sobretudo àqueles que contratam. É aqui que se localiza a terceira cultura apontada por Barbier, qual seja, "culturas do desenvolvimento de competências". Nessas "culturas", como apontado anteriormente, as aprendizagens estão relacionadas ao desenvolvimento de competências que acontecem em espaços de ação "real" dos sujeitos.

Dessa forma, a FLV se relaciona à empregabilidade dos indivíduos por fornecer conhecimentos e meios de adquirir e desenvolver novas competências. Insere-se tanto num campo de liberdade de escolhas quanto de necessidade ou se torna em verdade, um imperativo à medida que propicia ao trabalhador as condições necessárias para permanecer em atividade de modo produtivo. (FOURCADE, 2009).

O retorno das discussões sobre a FLV num momento em que o mundo do trabalho e da produção assistem a grandes mudanças traz consigo, também, as antigas críticas à vertente de entendimento dessa modalidade de formação, que se mostra mais comprometida com as abordagens patronais e de mercado. Segundo essas abordagens cabe ao trabalhador se adaptar e se responsabilizar por sua qualificação, evidentemente dentro de uma perspectiva do posto de trabalho.

A FLV se bate, então, numa luta antiga da educação profissional, ou seja, confronta-se à ideia de que o sistema educativo deva oferecer às 
empresas uma mão de obra imediatamente operacional em detrimento de uma formação humana e social dos trabalhadores. A oferta de todas as bases de conhecimento e de saber-fazer de forma ampla não exclui a formação cidadã. Em outras palavras, não se forma o cidadão apenas para o trabalho, mas também para a sociedade e para a vida. Velha luta que encontra, ainda, sentido e lugar na mesma medida em que se continua a formar trabalhadores para os postos de trabalho.

Podemos dizer que a FLV é uma noção que surgiu e continua existindo a partir de duas abordagens diferentes: uma voltada para a formação humana e social do indivíduo, comum a todas as discussões e documentos produzidos por organizações internacionais, sobretudo pela UNESCO, desde a década de 1970; e outra, de caráter econômico, produzida por organizações como a União Européia (UE), a Organização para Cooperação do Desenvolvimento Econômico (OCDE), a Organização Internacional do Trabalho (OIT) que entendem a FLV como "[...] um instrumento a serviço de uma evolução considerada inevitável" (FOURCADE, 2009, p. 928).

Para concluir, diríamos que importante contribuição para o entendimento de Educação, Formação e Aprendizagem ao Longo da Vida se encontra, também, em Lima (2007) que, de certa forma, reforça o que foi exposto anteriormente e acrescenta a ideia de uma polarização das práticas educativas representadas por ele metaforicamente como estando "entre a mão direita e a mão esquerda do pintor Catalão Miró" (LIMA, 2007, p.7). Num movimento pendular, como entendemos sua metáfora, ainda que constrangidas por tensões as mais diversas, as práticas educativas estariam, para ele, por vezes mais próximas dos entendimentos da UNESCO e, por vezes, da OCDE.

Ainda que discordemos dessa metáfora ou do movimento pendular que ela representa, colocando limites à direita e à esquerda às práticas educativas, e por mais bela que possa parecer, e ela é, efetivamente, extrai-se da ideia desse autor algo que vai ao encontro do nosso entendimento e que se coloca como pano de fundo deste trabalho, qual seja, o trabalhador, ao procurar a formação profissional, ainda que ele busque saberes e conhecimentos que possam criar as condições de 
melhor se adaptar ao mercado, que se encontra em constante mudança, ele busca, também, responder as questões postas pela sua prática social e profissional, ou pelas situações vividas no seu cotidiano. E essa busca não nos parece ser atendida por uma formação profissional unicamente adaptativa. É nesse sentido que Lima (2007) se refere à mão direita e à esquerda de Miró.

\subsubsection{A FLV como formação humana e social do indivíduo}

Quando se fala de FLV não se está apenas evocando a formação profissional por oposição à formação geral. A FLV se articula, igualmente, à formação inicial, que pode ser profissional. Dessa forma, ela deve ser compreendida como a articulação entre os tempos de formação inicial, contínua e os tempos de trabalho ao longo da vida ou como a articulação entre os diferentes tempos sociais (FOURCADE, 2009).

A FLV está assentada sobre o desejo do trabalhador de encontrar no acesso ao conhecimento, as respostas às questões que emanam da sua prática social ou de sua prática profissional. Por assim dizer, na FLV o aluno só se formará se encontrar as respostas aos problemas que emergem da situação por ele vivida.

Assim, o ato de aprender na FLV não se faz no interior de uma lógica de programa estruturado de aquisição de conhecimentos, como ocorre, tradicionalmente, na escola. Nem é, muito menos, o prolongamento, sob outra forma, do projeto escolar de formação inicial, porque aprender, nesse sentido, é relacionar o que se aprende na ação aos conhecimentos científicos, ou seja, aprender é relacionar conceitos quotidianos a conceitos científicos, porque só assim a experiência pode ser fonte de autonomia e de emancipação (MERLE, 2006).

Não se trata, portanto, de inverter a pedagogia das crianças para se obter uma pedagogia dos adultos, ensina-nos esse autor; nem passar de uma abordagem dedutiva a uma abordagem indutiva. Da mesma forma, não há, de um lado, conhecimentos vulgares, adquiridos pela experiência e, de outro, conhecimentos nobres, produzidos pela ciência, mas uma dinâmica coletiva que vai de um a outro, não existindo um sem o outro. 
O sentido da FLV é desenvolver nas pessoas a capacidade de sair do que programaram para elas, de sugerir significado aos saberes que vão além do meio em que vivem, de permitir contato com o que é diferente, de construir um elo social estruturado em torno da ação coletiva, criando, assim, a oportunidade delas se organizarem na busca do aprendizado ao longo da vida.

Dessa forma, para aprender, é necessário cultivar a capacidade de abertura à alteridade, aprendendo a ouvir o outro, a respeitar o outro, a buscar o bem comum. Nesse sentido, “[...] a busca do bem comum não abole os interesses individuais que permanecem legítimos, mas continua sendo um princípio fundamental da educação, da aprendizagem e da formação ao longo da vida." (MEIRIEU, 2005, p.5). O que nos leva a acreditar, em concordância com esse autor, que o trabalho de FLV é algo nunca acabado.

Talvez se possa dizer que a Formação ao Longo da Vida, diferentemente de outras propostas de formação - formação tradicional, formação por competência, entre outras - esteja em colocar o aluno como centro da formação, mais especificamente o desejo do aluno de aprender, tornando mais clara a sua busca, as suas necessidades e contribuindo para mantê-lo mais motivado em aprender, sem, contudo, desconsiderar a importância dos saberes e da aprendizagem desses saberes.

É como se pudéssemos dizer que os saberes oferecidos nesse tipo de formação profissional são saberes teóricos e técnicos, necessários e presentes nas formações tradicionais, porém, são também saberes significativos, à medida que se leva em conta não somente o que o aluno deve aprender, mas o que ele deseja aprender, por meio de uma proposta de mobilização dos saberes. Ou seja, a FLV oferece uma formação relevante para aquele que aprende, fazendo parte do desejo individual de aprender e de buscar conhecimentos, mas, também, oferta saberes que o ajudam a atender as mudanças e transformações do setor em que trabalha ou virá a trabalhar.

Portanto, a FLV é uma formação que ensina, mas também prepara e motiva o aluno para atuar de forma mais autônoma no trabalho e fora dele, tornando-o capaz de construir reflexivamente projetos de vida e 
de sociedade. Ela está associada à ideia de aquisição permanente de conhecimentos em todos os níveis da sociedade e a de desenvolvimento da pessoa por meio do acesso a esse conhecimento (MERLE, 2006; MEIRIEU, 2005).

Mas a aquisição permanente de conhecimentos em nada se relaciona a uma "interminável sucessão de formações e de aprendizagens úteis e eficazes, segundo apenas uma determinada racionalidade de tipo econômico e gerencial" , mas antecede a essa aquisição a "substantividade da vida ao longo da educação" (LIMA, 2007 p.10).

A FLV é, finalmente, uma tentativa constante de colocar em tensão o desenvolvimento das atitudes e as capacidades fundadas sobre a experiência e a apropriação no interior da atividade dos conhecimentos e dos conceitos científicos. Trata-se do momento privilegiado no curso da vida profissional e pessoal em que o sujeito tenta construir, com a ajuda de um terceiro, a continuidade entre a experiência e o conhecimento socialmente constituído, sendo o formador esse outro sujeito que contribui para essa construção social.

\subsubsection{O formador}

A educação, como nos ensina Freire (2004, p.67), “[...] não pode ser a do depósito de conteúdos, mas, a da problematização dos homens em sua relação com o mundo." A problematização, todavia, não se faz a partir de homens compreendidos como "vazios" de conhecimentos e deixados aos outros a responsabilidade de ensiná-los ou de preencher esses vazios. Assim, torna-se necessário que o formador mude a sua forma de ensinar, que estabeleça trocas, que se forme enquanto forma o outro e que esse outro se torne sujeito do processo formativo estabelecendo trocas e crescendo juntos.

Jobert (2006, p.3) explica que ao longo da história da formação de adultos e dentro de uma abordagem reformista os formadores diversificaram seus objetos de intervenção. Essa diversificação de ação orientada por eles teve esquematicamente "três entradas de ação": intervenção sobre as pessoas, sobre as estruturas e sobre o trabalho. 
No primeiro tipo de intervenção, o aluno é orientado pelo formador a modificar a sua relação com atos, objetos, contextos e o sentido próprio de sua ação. Por vezes, em termos de formação, o formador leva em conta não apenas a formação do sujeito cognitivo, ou seja, o sujeito epistêmico, mas também o sujeito engajado em todas as dimensões - emocionais, imaginárias, sociais, simbólicas - estando aqui posta a diferença entre o trabalho do formador e o do professor.

Ainda de acordo com Jobert (2006), importa ao formador diferenciar o que os adultos fazem, por meio do pensamento, daquilo que eles fazem na prática, compreendendo o uso prático que no futuro poderão fazer do que aprenderam.

Entre os anos 1960 e 1980 os formadores passam a buscar um tipo de intervenção "socioeducativa" (JOBERT, 2006, p.5) produzindo, segundo esse autor, efeitos estritamente formativos, mas com efeitos culturais difusos e duradouros.

Assim sendo, o intervir sobre as estruturas, mesmo obtendo efeitos, ainda que modestos, não alcançou o êxito almejado. Tanto um modelo quanto outro não levou em conta o agir humano no trabalho e toda a dimensão de conhecimento e aprendizagem estabelecida nessa relação (terceiro tipo de intervenção apresentada por esse mesmo autor).

No trabalho ora apresentado os formadores são alunos dos cursos de engenharia do CEFET-MG, que conduzem cursos voltados para algumas áreas da construção civil oferecidos aos trabalhadores desse setor. No exercício de suas atividades como formadores eles estabelecem relações com os alunos trabalhadores, que dão forma a uma prática educativa que tem como referência a FLV.

O que torna, então, os alunos dos cursos de engenharia do CEFETMG, formadores? O PROGEST, grupo de pesquisa em que se encontram os alunos dos cursos de engenharia do CEFET-MG participantes da pesquisa como formadores, não oferece a eles um curso que os capacite como tais. Nesse sentido, eles se encontram numa situação semelhante à grande maioria de seus próprios professores, que saídos das universidades, de cursos de mestrado ou doutorado, entram nas salas de aula na condição de professores. 
Os jovens alunos de engenharia de posse de saberes adquiridos nos seus respectivos cursos e da experiência como alunos que são, há vários anos, poderiam, num processo de imitação de seus professores, tão somente reproduzir as práticas educativas e comportamentos tais como as observadas em sala de aula pelos que ensinam. O que os levaria, então, a agir diferentemente?

Poderíamos supor que, ao se inscreverem como candidatos a formadores a única referência que portam ou a mais marcante e que pensam poder levar consigo para as salas de aulas é a aprendida com os seus professores. Mas não é exatamente o que ocorre. Ao assumirem as salas de aula eles se deparam com outra realidade e desafios que nem de longe poderiam imaginar: pessoas muito mais velhas que eles, profissionais com grande experiência nos trabalhos de canteiros de obras, que lá se encontram por iniciativa própria e não porque foram obrigados pelas empresas em que trabalham. Eles descobrem rapidamente que não apenas podem ensinar, mas podem, também, aprender com os alunos trabalhadores o que não aprenderam na faculdade, o que, aliás, é um dos fatores que os motivam a se candidatar a formadores. Em outras palavras, eles descobrem que, diante de tanta experiência e as mais diversas trazidas pelos trabalhadores, os seus saberes, mesmo importantes e desejados pelos seus alunos, não lhes permitem uma conduta professoral, ainda que professores fossem. Eis aí uma velha questão tratada por Bachelard (1996) numa crítica às "cabeças benfeitas", professorais e mesmo arrogantes.

Eles descobrem, ainda, que precisam construir outro tipo de relação com esses alunos, diferentemente daquela que poderiam estabelecer, imitando os seus professores. É preciso criar um ambiente em que ambos, formadores e alunos trabalhadores, num ambiente democrático, aprendam o que desejam ou precisam aprender.

Desde o primeiro momento, então, que procuram o PROGEST eles estão imbuídos da ideia de que estabelecerão uma troca com os alunos trabalhadores. Eles trocam os seus saberes teóricos pelo saber-fazer, pela experiência dos alunos trabalhadores. Mais do que isso, mais do que um espaço de pura troca, a sala de aula se torna num espaço de encontro e 
de interação de saberes.

No decorrer da aula pude interagir melhor com os alunos, deixando claro que, assim como eles, ainda sou um aluno e que não estou lá para ensinar, mas também para aprender com as experiências que cada um já vivenciou. (Formador, 21 anos, $3^{\circ}$ período do curso de Engenharia Elétrica)

Apesar das dificuldades que todos os formadores têm em suas primeiras aulas, eles são ajudados pelos colegas veteranos que thes passam informações consideradas por eles úteis para melhorar os métodos de ensino. Mudanças e problemas são discutidos por todo o grupo e todos têm a opinião respeitada e as decisões são, assim, tomadas de forma democrática.

Esse tipo de atitude, dentro de um grupo voluntário como o do PROGEST, colabora para o bom relacionamento entre os integrantes, que, por sua vez, ajuda a manter a qualidade dos cursos.

Prezo muito as pessoas que estão trabalhando comigo. Nosso ambiente de trabalho é bastante dinâmico e democrático. Nossas decisões são previamente discutidas e analisadas para chegarmos a um consenso para o desenvolvimento do projeto que, tanto eu como os outros integrantes do grupo de pesquisa defendemos. (Formador, 22 anos, $6^{\circ}$ período do curso de Engenharia Elétrica).

\section{Trabalhadores da construção civil num projeto de FLV}

A formação e a qualificação profissional, tradicionalmente construídas nos canteiros de obras, têm se mostrado insuficientes, em especial nas grandes obras ou nas grandes construtoras, para acompanhar as mudanças e demandas da construção civil. Na atualidade e cada vez mais, elas atendem a formação escolar de forma complementar, ainda que muito importantes. Tal fato contribui para levar o trabalhador da construção civil de volta à escola, continuando, ele próprio, a se responsabilizar por sua formação, como historicamente sempre ocorreu com os trabalhadores do setor (Tomasi, 1999), visto que, no Brasil, só muito recentemente, o setor da construção civil, em especial o subsetor edificações, tem demonstrado maior interesse em investir na formação profissional de seus trabalhadores. 
Atualmente algumas iniciativas para formar os trabalhadores por parte de sindicatos, escolas e outras instituições públicas ou particulares, ainda que dispersas, ganham relevância. As iniciativas sugerem, em grande medida, estar voltadas para o atendimento de demandas específicas do mercado de trabalho, velho problema que se coloca na relação empresa/escola. Tal fato nos levou a questionar sobre uma formação profissional que não tenha essas demandas como referências primeiras, mas sim o desejo do trabalhador de aprender ou o que ele quer aprender.

\subsection{Os trabalhadores pesquisados}

Desde 2003 operários da construção civil da Região Metropolitana de Belo Horizonte buscam os cursos de Gestão de Obras e de Instalações Elétricas Prediais oferecidos pelo Programa de Estudos em Engenharia, Sociedade e Tecnologia (PROGEST), um grupo de pesquisa do CEFETMG que desenvolve pesquisas no campo da formação e da qualificação de trabalhadores da construção civil, inclusive de engenheiros do setor.

O curso de Gestão de Obras tem uma carga horária de 240 horas distribuídas em 30 semanas e o de Instalações Elétricas Prediais de 120 horas distribuídas em 15 semanas, ambos com aulas somente aos sábados. Eles são conduzidos pelos alunos dos cursos de Engenharia Civil e de Engenharia Elétrica, reconhecidos pelas suas práticas como formadores, no sentido estrito do que foi acima discutido.

Nos $1^{\circ}$ e $2^{\circ}$ semestres de 2010 e 2011, período base da pesquisa realizada, o PROGEST teve 376 candidatos inscritos no processo seletivo para o curso de Gestão de Obras e 380 para o de Instalações Elétricas Prediais, totalizando 756 candidatos.

Nesse mesmo período estavam matriculados 114 alunos trabalhadores no curso de Gestão de Obras e 102 alunos do curso de Instalações Elétricas Prediais, totalizando 216 alunos trabalhadores.

Os trabalhadores que buscam esses cursos, assim o fazem por iniciativa própria e não por iniciativa das empresas nas quais trabalham e, muito menos, recebem qualquer ajuda delas para tal. Em alguns 
casos as empresas desconhecem que eles estão realizando os cursos e quando descobrem isso nem sempre lhes agrada, porque sentem que não podem contar com a dedicação exclusiva dos trabalhadores. Não há, também, qualquer garantia de que a realização dos referidos cursos possa representar, para os trabalhadores, promoções, aumento de salários ou outros ganhos, ainda que, em alguns casos, isso tem acontecido.

O trabalho que aqui se descreve se apoia em pesquisas de Tomasi e Ferreira $(2010,2011)$ e constitui parte importante da pesquisa financiada pela FAPEMIG e conduzida por Ferreira (2012), A Formação ao Longo da Vida (FLV). Um estudo sobre a formação profissional de trabalhadores da Construção Civil.

O trabalho ora apresentado não discorrerá sobre o conjunto de dados coletados junto aos trabalhadores - candidatos e aos já alunos dos cursos (questionários, entrevistas e documentos), ainda que, como referência, alguns dados colhidos sejam lembrados. Serão considerados tão somente extratos de entrevistas semiestruturadas aplicadas em 20 alunos do curso de Gestão de Obras escolhidos aleatoriamente dentre os 114 trabalhadores alunos do referido curso, que se encontravam matriculados nos $1^{\circ}$ e $2^{\circ}$ semestres de 2010 e 2011 . Dificuldades encontradas ao longo do curso impediram que os alunos de Instalações Elétricas participassem da entrevista.

Foram entrevistados, também, cinco formadores dos cursos e extratos dos depoimentos de dois deles se encontram aqui expostos.

Para se candidatar ou se matricular no curso não há qualquer exigência formal quanto à escolaridade, basta que o interessado seja aprovado numa prova que tem como referência os conteúdos do ensino fundamental. Registre-se, contudo, que cerca de metade dos candidatos dos dois cursos declarou, no ato da inscrição, possuir o ensino médio completo ou incompleto. Os candidatos ao curso de Instalações Elétricas Prediais, todavia, declararam possuir uma escolaridade superior aos do curso de Gestão de Obras. Quanto ao tempo de trabalho na construção civil, metade destes últimos se divide entre os que têm entre um e cinco anos de canteiro de obras e os que têm mais de 15 anos. No curso de Gestão de Obras, candidatos e alunos com mais de 15 anos de canteiro 
de obras são cerca de um terço deles. Quanto à idade estes últimos se encontram na maioria entre 31 e 50 anos, ou seja, 65,4\%. Entre os candidatos e alunos do curso de Instalações Elétricas Prediais, 50\% tem essa mesma faixa etária.

\subsection{O que dizem os alunos trabalhadores entrevistados?}

Não obstante os limites da amostra utilizada, o que não nos permite uma generalização sem riscos de graves equívocos, não é difícil constatar que os alunos trabalhadores desejam prioritariamente o acesso a conhecimentos que eles denominam "teóricos". Para eles, teórico é o que se mostra exposto em linguagem outra que não a que habitualmente convivem profissionalmente. Seriam, então, os cálculos matemáticos, os projetos (arquitetônicos, estruturais, elétricos, hidráulicos), os materiais e sua composição e os processos construtivos, entre outros.

$\mathrm{O}$ interesse deles, como pode se depreender nos depoimentos abaixo parece estar nitidamente associado ao desejo de compreender a sua prática cotidiana, o seu fazer, ou seja, entender o que fazem no dia a dia. Esse desejo pode estar também associado a outro, qual seja, o de autonomia ou de construção ou direcionamento de seu projeto profissional.

Eu comecei a entender de tecnologia de construção. Antes, não, eu fazia era porque via alguém fazer. (Pedreiro, 44 anos, ensino médio, 14 anos na construção civil)

Muito conhecimento que eu adquiri... Eu sou encarregado. Eu aprendi tudo na obra mesmo, trabalhando lá. Então, muita coisa que eu sei fazer e num entendo como é, porque que eu estou fazendo aquilo, eu estou entendendo aqui, entendeu? (Encarregado, 37 anos, ensino fundamental, seis anos na Construção Civil)

Eu já sabia executar projeto elétrico, mas eu lia e fazia e não sabia por que era assim. Hoje, não, hoje eu sei pegar qualquer planta e saber por que o rapaz colocou aquele disjuntor, porque é aquele fio, porque é cada coisa. Imagina para você ver, você sabe fazer, mas você sabe o porquê daquilo. Para mim faz muita diferença. (Pedreiro, 40 anos, ensino fundamental, 20 anos na construção civil) 
Hoje eu sei fazer o trabalho e sei explicar o porquê do serviço que eu estou fazendo. E até mesmo dentro da empresa onde eu trabalho, já ficou bem mais fácil a linguagem técnica, para poder conversar com o engenheiro, o encarregado... Melhorou bastante. (Pedreiro, 36 anos, ensino médio, 10 anos na construção civil)

Eles estão em busca, também, de saberes relacionados à comunicação, ou seja, buscam adquirir um domínio da comunicação, da linguagem e seus símbolos, compreender as filigranas da língua, não apenas acadêmica, mas também técnica, o que lhes permitiria melhor transmitir os seus conhecimentos, adquirir outros e se comunicar de igual para igual com os superiores, sobretudo com os engenheiros, como ilustra o depoimento de um dos entrevistados:

Antes eu não conseguia conversar bastante e, hoje, eu converso até demais. Tenho um relacionamento com as pessoas bem melhor, tenho uma capacidade até de liderar mesmo com mais facilidade. (Pedreiro, 36 anos, ensino médio, 10 anos na construção civil)

Muito embora se possa argumentar que esses saberes e a aquisição dos conhecimentos relativos a eles se prestam a atender a demandas do mercado, sobretudo as relacionadas às atuais mudanças no setor da construção civil, mesmo porque concluído o curso os alunos fazem questão de receber o certificado e apresentá-lo à empresa em que trabalham em busca de promoção, aumento de salário e outros benefícios, é importante também registrar que nem todos os conhecimentos buscados estão relacionados ao seu trabalho nos canteiros de obras ou visem propriamente o canteiro.

Ter um certificado emitido pelo CEFET-MG e ter conhecimentos até então estranhos a eles contribui enormemente, como afirmam, para o reconhecimento social e o reconhecimento dos filhos, da esposa e dos demais familiares e amigos. Mais do que isso esses conhecimentos parecem dar-lhes uma autoestima que até então não possuíam.

Eu passei em décimo lugar na classificação. Eu aproveitei e falei: Filha, o seu pai é dez! (risos). Lá em casa você tem que ver que legal que é. Algumas notas eu perdia pouco percentual, eu chegava assim com um semblante triste em casa e falava que tinha ficado chateado porque perdi três décimos na prova de matemática. Não gostei. Minha filha dizia: Que isso pai? Que isso? (Pedreiro, 40 
anos, ensino fundamental, 20 anos na construção civil)

[...] ano passado, meu menino estava fazendo curso técnico e queria até parar com o curso. Aí eu falei: Você vê, eu tenho mais idade que você e estou estudando dois cursos, batalhe! Aí ele resolveu, continuou nos estudos, hoje trabalha no Bradesco, técnico de eletrônica e tem uma boa estabilidade dentro da empresa, então fez a diferença. Até mesmo os vizinhos, você vê que eles te olham com outros olhos, dentro da empresa, também. (Pedreiro, 50 anos, ensino médio, 15 anos na construção civil)

Fica claro nos depoimentos dos alunos trabalhadores a necessidade que possuem de serem reconhecidos como capazes, como competentes e isso não apenas por seus colegas de trabalho ou pelos seus próximos, mas pela sociedade, de modo geral.

Querendo ou não, você sofre preconceito da sociedade quando você fala que trabalha na construção civil. Peão, tudo mal educado, só sabe trabalhar, analfabeto, burro. O cara que hoje convive na construção civil vê que é totalmente diferente. É um lugar onde você pode trabalhar e criar uma convivência sadia, um ambiente muito descontraído. (Pedreiro, 21 anos, ensino médio, um ano na construção civil)

A formação profissional, sobretudo a formação que lhes dá voz e oportunidade de participarem como sujeitos do processo educativo tem, para eles, um sentido revolucionário, qual seja o de se sentirem como iguais aos seus superiores, no caso, os engenheiros, entre outros. Ou de se sentirem mais seguros, mais confiantes, porque se antes eles sabiam fazer, agora eles sabem explicar o que fazem. Isso pode, inclusive, fazêlos se sentirem um passo à frente dos engenheiros que não sabem fazer.

\section{Considerações finais}

Os depoimentos dos trabalhadores pesquisados não nos permitem afirmar com precisão os saberes que eles buscam ao procurar os cursos de formação profissional oferecidos pelo PROGEST. Esses saberes são por eles denominados de forma ampla, de teorias. A imprecisão ao apontarem o que buscam pode estar relacionada ao fato de cerca de metade deles ter, no máximo, o ensino fundamental incompleto. Parece- 
nos, entretanto, bastante evidente que os conhecimentos que construíram ao longo do curso respondem a um desejo de compreenderem as suas práticas profissionais cotidianas, assim como discutida por autores da FLV. Ou seja, eles detectam no que chamam de teoria uma força explicativa para o que fazem, que é o que parecem finalmente buscar.

A explicação do mundo ou, em outras palavras, a sua decodificação pela via da "teoria" pode ajudá-los a experimentar uma autonomia e construir um projeto de futuro pessoal ou profissional. Isso é possível porque a prática educativa na qual estão envolvidos viabiliza, a partir das relações que estabelecem com o formador, a sua condição de protagonista do seu processo de formação. São as indagações sobre o seu fazer, sobre a sua experiência profissional que, numa certa medida, ganham relevância na sua relação com o formador.

O curso realizado permitiu-lhes, ainda, o acesso a uma linguagem, em especial técnica, que lhes favorece a comunicação com os engenheiros e outros condutores dos trabalhos de canteiros, o que melhor expõe e valoriza os seus conhecimentos e as suas competências construídas na situação de trabalho.

Parece advir desses fatos, um reconhecimento social (empresa, família, comunidade em que habitam), que lhes parecia até então negado. E, da mesma forma, novas possibilidades de vida. Possibilidades para além dos limites que pareciam próximos. Ou seja, eles fizeram contato com o estranho, com o diferente, mas, mais do que isso, aprenderam a se organizar na busca do novo, sobretudo de novos conhecimentos.

Assim, se não podemos apontar exatamente que saberes buscam os trabalhadores pesquisados, isso não significa que eles não sabem o que querem aprender. Diferentemente disso, não é difícil afirmar que eles sabem o que querem, e, no caso, eles parecem se aproveitar da FLV para ensaiar um movimento de apropriação dos saberes e da cultura dominante como forma de serem reconhecidos socialmente. 


\section{Referências}

BACHELARD, G. A formação do espírito científico. Contribuição para uma psicanálise do conhecimento. Rio de Janeiro: Contraponto, 1996.

BARBIER, J-M. Le champ de la formation des adultes. In: BARBIER, J. M.; BOURGEOIS, E.; CHAPELLE,G.; BORBALAN, J. (Org.). Encyclopédie de la formation. Paris: Presses Universitaires de France, 2009. p. 1-28.

BOSHIER, R. W. Edgar Faure after 25 years: down but not out. In: HOLFORD, J.; JARVIS, P.; GRIFFIN, C. International perspectives on lifelong learning. London: Kogan Page, 1998, p. 3-20.

BOURNAZEL, A. L'éducation tout au long d'une vie: une nouvelle education nationale, Paris: Ellipses, 2001. p.16.

DUGUÉ, E. A lógica da competência: o retorno do passado. In: TOMASI, A. (Org.). Da qualificação à competência: pensando o século XXI. Campinas: Ed. Papirus, 2004. p.19-32.

DURKHEIM, E. Educação e sociologia. São Paulo: Fename, 1973.

FERREIRA, J. E. R. M. A formação ao longo da vida - FLV: um estudo sobre a formação profissional de trabalhadores da Construção Civil. 2012. 120 f. Dissertação (Mestrado em Educação Tecnológica) - Centro Federal de Educação Tecnológica de Minas Gerais (CEFET-MG), Belo Horizonte, 2012.

FOURCADE, B. La formation tout au long de la vie. In: BARBIER, J. M.; BOURGEOIS, E.; CHAPELLE, G.; BORBALAN, J. (Org.). Encyclopédie de la formation. Paris: Presses Universitaires de France, 2009. p. 915-955. 
FREIRE, P. Pedagogia do oprimido. 39. ed. Rio de Janeiro: Paz e Terra, 2004.

FRIEDMANN, G. O Trabalho em migalhas. S. Paulo: Perspectiva, 1972.

HARPER, B. et al. Cuidado, escola! Instituto de Ação Cultural - IDAC. São Paulo: Brasiliense, 1980.

JOBERT, G. Les formateurs d'adultes et l'idéologie du changement. Comité Mondial pour l'éducation et la formation tout au long de la vie. Paris: UNESCO, 2006.

LIMA, L. C. Educação ao longo da vida. Entre a mão direita e a mão esquerda de Miró. São Paulo: Cortez, 2007.

MÉHAUT, Ph. Knowledge economy, learning society and lifelong learning: a review of the french Literature, Document de travail (LEST - CNRS), Université de Provence et Université de la Méditerranée, Provence, 2004.

MEIRIEU, P. Aprender... sim, mas como? Porto Alegre: Artes Médicas, 1998.

MEIRIEU, P. Éducation et formation tout au long de la vie. Comité Mondial pour l'éducation et la formation tout au long de la vie. Paris: UNESCO, 2005.

MERLE, V. Apprendre tout au long de la vie: pourquoi, comment? Comité Mondial pour l'éducation et la formation tout au long de la vie. Paris: UNESCO, 2006.

PIRES, A. L. Educação e Formação ao Longo da Vida: análise crítica dos sistemas dispositivos de reconhecimento e validação de aprendizagens e de competências. 2005. Tese (Doutorado) - FCT/ UNL. Lisboa: Fundação Calouste Gulbenkian/Fundação para a Ciência e a Tecnologia, 2005. 
ROGERS, C. Grupos de encontro. Lisboa: Martins Fontes, 1974.

TOMASI, A. A construção social da qualificação dos trabalhadores da construção civil de Belo Horizonte: um estudo sobre os mestres de obras. 1999. 120 f. Relatório de Pesquisa (Sociologia/CNPq) - Faculdade de Filosofia e Ciências Humanas, UFMG, Belo Horizonte: 1999.

TOMASI, A. P. N.; FERREIRA, J. E. R. M. Capacitação de operários da construção civil da RMBH - Brasil: avaliando o desenvolvimento pessoal e profissional. In: CONGRESSO INTERNACIONAL DE AVALIAÇÃO EM EDUCAÇÃO, 2., 2010, Braga. Anais... Braga: Universidade do Minho, 2010.

TOMASI, A. P. N.; FERREIRA, J. E. R. M. A formação profissional na França: ofícios da construção. In: CONGRESSO BRASILEIRO DE EDUCAÇÃO EM ENGENHARIA, 39., 2011, Blumenau. Anais... Blumenau: ABENGE, 2011.

USHER, R.; BRYANT, I.; JOHNSTON, R. Adult education and the postmodern change. London: Routledge, 1997.

ZARIFIAN, Ph. Le travail et l'événement. Paris: Editions l'Harmattan, 1995.

Recebido: 10/03/2013

Aprovado: 12/07/2013 